\title{
Idiopathic Hypoparathyroidism Presenting As New Onset Refractory Status Epilepticus
}

\author{
Saranya B. Gomathy ${ }^{1}$ Divya M. Radhakrishnan ${ }^{1} \quad$ Animesh Das $^{1} \quad$ Achal K. Srivastava $^{1}$
}

${ }^{1}$ Department of Neurology, All India Institute of Medical Sciences, New Delhi, India

J Neurosci Rural Pract 2021;12:796-797.
Address for correspondence Divya M. Radhakrishnan, MD, DM, Department of Neurology, Room No 602, 6th floor, CN center, All India Institute of Medical Sciences, New Delhi 110029, India (e-mail: dr.divyamr@gmail.com).
A 23-year-old male, presented with a flurry of new onset generalized tonic clonic seizures and impaired sensorium. He was intubated and managed as a case of status epilepticus with intravenous lorazepam followed by multiple anti seizure medications (ASM) and midazolam infusion. His initial laboratory reports revealed hypocalcemia $(4.8 \mathrm{mg} / \mathrm{dL})$ (ref range: $8-11 \mathrm{mg} / \mathrm{dL}$ ) with normal sodium, potassium, magnesium, and phosphorus levels. His blood sugar, renal, and liver function tests were also within normal limits. Further evaluation showed low intact parathyroid hormone
$<3 \mathrm{pg} / \mathrm{mL}$ (ref range: $15-68.3 \mathrm{pg} / \mathrm{mL}$ ) and Vitamin D3 (22 ng/mL) (ref range 30-100 ng/mL) levels. Computed tomography (CT) of brain showed calcifications in bilateral caudate, lentiform nucleus, and cerebellar hemispheres (-Fig. 1A, B). Ultrasound abdomen and CT scan of neck were normal. With the diagnosis of idiopathic hypoparathyroidism, he was treated with parenteral and oral calcium preparations, along with Vitamin D3 under cardiac monitoring. With correction of hypocalcemia his seizures got controlled; he was extubated and ASM were tapered. He

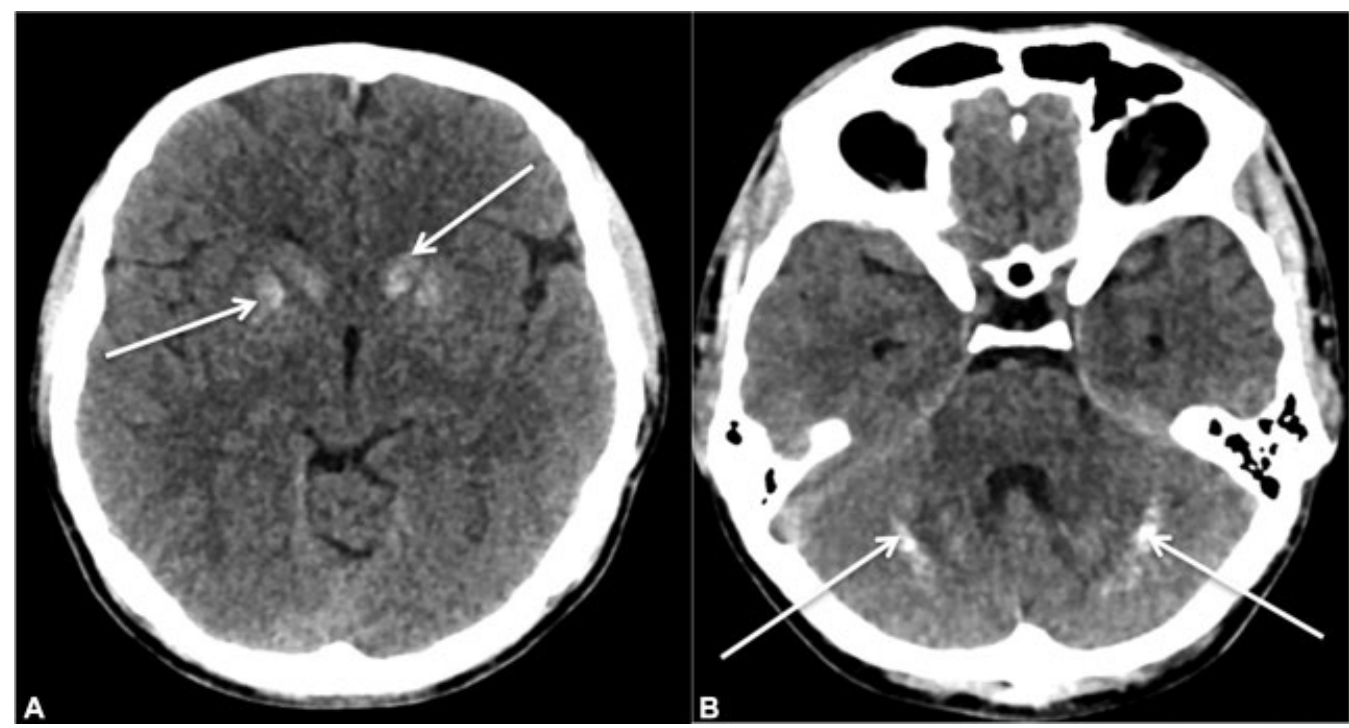

Fig. 1 (A) Non-contrast computed tomography (NCCT) head axial view showing bilateral calcification of caudate nucleus and putamen (white arrows). (B) NCCT head axial view showing cerebellar calcification (white arrows).

published online September 16, 2021
DOI https://doi.org/ $10.1055 / \mathrm{s}-0041-1735247$. ISSN $0976-3147$. (c) 2021. Association for Helping Neurosurgical Sick People. All rights reserved.

This is an open access article published by Thieme under the terms of the Creative Commons Attribution-NonDerivative-NonCommercial-License, permitting copying and reproduction so long as the original work is given appropriate credit. Contents may not be used for commercial purposes, or adapted, remixed, transformed or built upon. (https://creativecommons.org/ licenses/by-nc-nd/4.0/)

Thieme Medical and Scientific Publishers Pvt. Ltd., A-12, 2nd Floor, Sector 2, Noida-201301 UP, India 
was discharged on oral calcium $(1,000 \mathrm{mg} / \mathrm{d})$ with calcitriol $(0.5 \mu \mathrm{g} / \mathrm{d})$ supplementation and was seizure free at 3 months follow-up.

Hypoparathyroidism is one of the most common cause of intracranial calcification (IC). Basal ganglia is the usual site and calcification beyond extrapyramidal system (cerebellum, thalamus, or subcortical white matter) is infrequent. ${ }^{1}$ Though seizures are noted in 30 to $70 \%$ of patients, new onset refractory status epilepticus as the presenting symptom of idiopathic hypoparathyroidism is extremely rare. ${ }^{2,3}$ Seizures are attributed to hypocalcemia and IC in vascular and perivascular area. ${ }^{4}$ Treatment of seizures includes prompt administration of high dose intravenous calcium followed by long-term oral supplementation of calcium and calcitriol. ${ }^{5}$ ASM that induce cytochrome P450 (CYP) isoenzymes can worsen hypocalcemia and should preferably be avoided in these patients. Hypocalcemia with IC can be a diagnostic clue for hypoparathyroidism; prompt treatment with calcium and vitamin D results in seizure freedom and prevents further neurological complications.

\section{Authors' Contributions}

S.B.M. contributed toward data collection and manuscript drafting. D.M.R. edited and reviewed the manuscript and also acted as a critique. A.D. and A.K.S. reviewed the manuscript and were also the critique.
Funding

None.

Conflict of Interest

None declared.

Acknowledgment

The authors acknowledge gratitude to their patient and family.

\section{References}

1 Mejdoubi M, Zegermann T. Neurological picture. Extensive brain calcification in idiopathic hypoparathyroidism. J Neurol Neurosurg Psychiatry 2006;77(12):1328

2 Liu MJ, Li JW, Shi XY, Hu LY, Zou LP. Epileptic seizure, as the first symptom of hypoparathyroidism in children, does not require antiepileptic drugs. Childs Nerv Syst 2017;33(02): 297-305

3 Nardone R, Brigo F, Trinka E. Acute symptomatic seizures caused by electrolyte disturbances. J Clin Neurol 2016;12 (01):21-33

4 Rizvi I, Ansari NA, Beg M, Shamim MD. Widespread intracranial calcification, seizures and extrapyramidal manifestations in a case of hypoparathyroidism. N Am J Med Sci 2012;4(08): 369-372

5 Shoback D. Clinical practice. Hypoparathyroidism. N Engl J Med 2008;359(04):391-403 